\title{
3-D. Aerodynamics and Thermal Prediction For Nassiriya Power Plant Furnace By Using Gaseous Fuel
}

\author{
Rafid M.Hannun ${ }^{1}$, Salih E.Najim ${ }^{2}$, Qais A. Rishack ${ }^{3}$, Nick Syred ${ }^{4}$ \\ ${ }^{1}$ Lecturer Dr. in Mech. (Thermal) Engineering, Vice Dean, College of Eng., Thi-Qar University, Iraq \\ ${ }^{2}$ Prof. Dr. in Mech. (Thermal) Engineering, College of Eng., Basrah University, Iraq \\ ${ }^{3}$ Assist.Prof.Dr. in Mech. (Thermal) Engineering, Head of Material Eng. Dept., College of Eng., Basrah \\ University, Iraq \\ ${ }^{4}$ Prof. Dr. in Mech. (Thermal) Engineering, School of Eng., Cardiff (Wales) University, UK
}

\begin{abstract}
The predictions of the features of high temperature systems (furnaces and/or boilers) are very important because they help and enable better decisions to be made about their effective operation; these predictions are made for an Iraqi Power Plant using the CFD FLUENT package. Temperature levels predicted are close to those measured $(2215.5 \mathrm{~K}$ predicted; $2152 \mathrm{~K}$ measured practically inside the furnace). In addition the velocity vectors are predicted with values commensurate with those produced by others as discussed in a literature review. NOx levels are subsequently studied in the context of using recirculated flue gases for emissions control.
\end{abstract}

\section{Nomenclature:}

\begin{tabular}{|c|c|c|c|}
\hline Symbol & definition & Symbol & definition \\
\hline $\begin{array}{l}\mathrm{G}_{\mathrm{m}} \\
\mathrm{G}_{\mathrm{t}} \\
\mathrm{U} \\
\mathrm{V} \\
\mathrm{W} \\
\mathrm{P} \\
\rho \\
\mathrm{R}, \mathrm{Z}, \theta \\
\mathrm{q}_{\mathrm{c.v} .} \\
\\
\mu_{\text {eff }} \\
\dot{m}_{f} \\
\mathrm{H}_{\mathrm{c} . \mathrm{v}} \mathrm{c}_{\mathrm{p}}\end{array}$ & $\begin{array}{l}\text { Axial thrust } \\
\text { Axial flux of angular momentum } \\
\text { Axial velocity }(\mathrm{m} / \mathrm{s}) \\
\text { Radial velocity }(\mathrm{m} / \mathrm{s}) \\
\text { Tangential velocity }(\mathrm{m} / \mathrm{s}) \\
\text { Static pressure }(\mathrm{pa}) \\
\text { Density }\left(\mathrm{kg} / \mathrm{m}^{3}\right) \\
\text { Radial, axial and tangential directions } \\
\text { Heat rate released per unit volume } \\
\left(\mathrm{W} / \mathrm{m}^{3}\right) \\
\text { Effective viscosity }\left(\mathrm{N} . \mathrm{s} / \mathrm{m}^{2}\right) \\
\text { Mass flow rate }(\mathrm{kg} / \mathrm{s}) \\
\text { Higher calorific value }(\mathrm{kJ} / \mathrm{kg}) \\
\text { Specific heat at constant pressure } \\
\left(\mathrm{kJ} / \mathrm{kg} .{ }^{\circ} \mathrm{C}\right)\end{array}$ & $\begin{array}{l}\lambda \\
\mathrm{M}_{\mathrm{f},} \mathrm{M}_{\mathrm{pr}} \\
\mathrm{m}_{\mathrm{pr}} \\
\frac{R}{R} \\
\mathrm{~T} \\
\mathrm{~m}_{\mathrm{a}} \\
\mathrm{T}_{\mathrm{f}} \\
\mathrm{T}_{\mathrm{a}} \\
\varepsilon \\
\sigma \\
\mathrm{A}_{\mathrm{p}}\end{array}$ & $\begin{array}{l}\text { Thermal conductivity }\left(\mathrm{W} / \mathrm{m} .{ }^{\circ} \mathrm{C}\right) \\
\text { Molecular weights of fuel and products of } \\
\text { combustion respectively } \\
\text { Mass of products in } \mathrm{kg} \text { per } \mathrm{kg} \text { of } \mathrm{O}_{2} \text {. } \\
\text { Universal gas constant in } \mathrm{kJ} / \mathrm{kmol} . \mathrm{K} \\
\text { Temperature in Kelvin. } \\
\text { Mass flowrate of the air }(\mathrm{kg} / \mathrm{s}) \\
\text { Highest core temperature }(\mathrm{K}) \\
\text { Ambient air temperature }(\mathrm{K}) \\
\text { Emissivity } \approx 0.8 \\
\text { Stefan }- \text { Boltzman constant }=5.67 \times 10^{-8} \\
\mathrm{~W} / \mathrm{m}^{2} . \mathrm{K}^{4} \\
\text { Area of the inside faces of furnace }\left(\mathrm{m}^{2}\right)\end{array}$ \\
\hline
\end{tabular}

\section{INTRODUCTION}

The furnace boiler is the important part of power plant the fuel is initially combusted and the heat transfer processes started. Industrial furnaces and boilers are widely used in power generation, manufacturing, processing, mining and refining industries to provide steam. The complex physico-chemical processes involved in flames have defied detailed analytical description until recently [1], and indeed now generally need experimental verification. The number of burners in water-tube furnaces may reach 50 depending on the particular design and operational requirement [2]. In the Nassiriya power plant in Iraq (case study), with drum type water-tube natural circulation boiler, steam is generated in the vertical tubes arranged to form the walls of the furnace chamber, this steam and water then pass to the boiler drum where the steam is separated and remaining water, together with the incoming feed water, is returned to the furnace water-tubes through pipes outside the furnace, called downcomers. Steam leaving the boiler drum enters the superheater, where it receives further heat before passing to the turbine. Steam which has partially expanded through the turbine may be returned to the plant and superheated again in the reheater.

Herein, the interest is to study the aerodynamic of the flow of fuel and air entering the furnace via swirl burners, the subsequent combustion processes and effects on the temperature distribution and other properties of the gas products in the axial, radial, and tangential directions for gaseous fuel by using the finite volume analysis and FLUENT programme. 
Some of variables such as the mean velocity of fuel and air are estimated from the mass flow rates and also the temperatures of the furnace, and the pressure is calculated by an empirical equation provided by the contracting company for the power plant.

The section reviews relevant literature in the area and especially the use of CFD to optimize similar systems and individual components. Beer and Chigier (1972) [4] presented a study of combustion aerodynamics with swirling flow, proposed some o non dimensional criterion to characterize the amount of rotation to the axial flow, deriving a well known parameter.

Syred and Beer (1974) [5] made extensive intensive isothermal tests with a tangential swirl burner, Swirling Number 2.2, they found a large toroidal recirculation zone in the exit occupying up to $75 \%$ of the exit diameter. Kilik (1976) [6] presented descriptions of several types of single air swirler for combustors. He found that all the velocity components decay in the downstream direction and after the stagnation point the reverse axial velocities disappear and as the effect diminishes the peak of the axial velocity profile shifts towards the centerline. He showed that the size of the recirculation zone is increased as a result to many parameters. Najim (1979) [7] measured three components of velocity with practical experiment on a cyclone combustor by using laser Doppler anemometry and so kinetic energy of turbulence in isothermal and combustion conditions. He concluded that the turbulence levels of the axial components were very high particularly in the annular recirculation zone and the tangential velocity fluctuations were low. Arscott et.al. (1980)[8] investigated the distribution of air and fuel in an oil fired boiler of 500MW which had 32 burners on the front wall; they deduced that there was an overall standard deviation of $3.7 \%$, which is probably quite small in comparison with the majority of boilers, but the bias between the two sides of the boiler was 3.5\%. Sislian et.al. (1988) [9] measured experimentally mean velocity components, turbulent intensities, velocity probability density functions, power spectra and autocorrelation functions of axial velocity fluctuation and spatial turbulence macroscale which were reported in a turbulent round jet flow issuing vertically into stagnant air in non combusting and combusting situations. The fuel density (a mixture of methane and argon) was chosen to be equal to the cold flow gas density (a mixture of air and helium) in order to minimize cold fuel/ cold gas mixture density difference effects on measured turbulence properties. A one dimensional laser Doppler velocimeter was used to obtain the measurements, and the temperature was measured by thermocouples. They concluded that turbulence in the jet diffusion flame was appreciably more anisotropic than in the corresponding cold jet in all regions of the flow. Thus the combustion process had been found to have a marked influence on the turbulence macroscale which was significantly smaller than in the cold jet flow in the upstream region and increased appreciably at downstream distances.

Cheng et.al. (2000)[10] investigated the viability of a low Swirl Number burner (LSB) which had been scaled to the thermal input levels of small industrial size for use in commercial and industrial furnaces and boilers. The original internal diameter was $5.28 \mathrm{~cm}$, this was then was scaled to $10.26 \mathrm{~cm}$ internal diameter and investigated up to a firing rate of $\mathrm{Q}=586 \mathrm{KW}$, then two LSB (5.28 and $7.68 \mathrm{~cm}$ internal diameter) were configured to accept a novel vane-swirler design and were evaluated up to $\mathrm{Q}=73 \mathrm{KW}$ and $280 \mathrm{KW}$, respectively. The emissions of the vane- LSB for 210 and $280 \mathrm{KW}$ output operating $0.8<\Phi<0.9\left(\mathrm{NO}_{\mathrm{x}}<15 \mathrm{ppm}\right.$ and $\left.\mathrm{CO}<10 \mathrm{ppm}\right)$ indicated a strong potential for applying LSBs to practical applications. Azazi (2001) [11] presented a study of the Hartha power plant furnace in Iraq, this furnace had square dimensions, pressurized and tangential corner firing. He used a two dimensional aerodynamics and thermal FORTRAN computer programme and concluded that the predicted pressure inside the fire-ball and in the furnace was in agreement with the design value. The furnace losses were $14.5 \%$ for $1500 \mathrm{C}^{\circ}$ inside temperature and the tangential velocity levels were vital in maintaining the stability of the fire ball. Nemoda et.al. (2005) [12] presented results of experimental and numerical investigations of a swirl cylindrical burner with turbulent flow with Swirl Numbers ranging from 0.85 -2.48 both under isothermal and combustion conditions. Mathematical models of the processes consisted of: turbulent swirl flow, convective heat and mass transfer, chemical reactions, radiative heat transfer. They showed that flows with higher swirl number provide smaller intensive combustion zones that located near the gas inlet regions, thus, flow regimes with a more intensive swirl produce better reaction conditions and better combustion efficiency. Sobolev et.al. (2008)[13] presented a numerical calculation for methane turbulent diffusion jet flames of a rectilinear-swirl burner in the furnace of a high capacity boiler by using the CFD AnsysCFX10.0 programme. They used standard furnace of height $30 \mathrm{~m}$, burner diameter $0.9 \mathrm{~m}$, furnace wall temperature $410^{\circ} \mathrm{C}$, air inlet temperature $297^{\circ} \mathrm{C}$, and fuel temperature $7^{\circ} \mathrm{C}$. They demonstrated the influence of the swirl on the central jet flow of the oxidizer, its effects on the flame structure and the calculation results for NOx production; they found that the average concentration of NOx $0.1-0.2 \mathrm{~g} / \mathrm{m}^{3}$. This modeling data agreed well with real measurements $\left(0.14-0.22 \mathrm{~g} / \mathrm{m}^{3}\right)$.The NOx production was in the range of $2.6-3 \mathrm{gNOx} / 1 \mathrm{kgCH}_{4}$, which agreed well with literature data [6]. Anand and Jenny (2009) [14] developed a study of a unified PDF modeling framework and a new hybrid solution algorithm to simulate turbulent evaporating sprays by using EulerianLagrangian-Lagrangian approach. To enhance the computational efficiency, a local particle time-stepping algorithm was implemented and a particle time-averaging technique was employed to reduce statistical and bias 
errors. Hannun et.al. (2011) [15] presented a study for Nassiriya power plant furnace by using crude oil fuel with FLUENT code to measure many parameters; temperature, pressure, combusted mixture velocity and species concentration.

\section{CASE STUDY FUNCTION}

The boiler of is of type TГME-206, (Russian TECHNOPROM Company) with natural circulation and is intended for the high pressure steam production for natural gas and fuel oil firing [3].

\subsection{Furnace Chamber}

The shape of the furnace chamber is prismatic; the dimensions are $7680 \times 18000 \mathrm{~mm}$, furnace chamber capacity is 2160 cubic metre. Furnace chamber walls are made of tubes with diameter $60 \times 6 \mathrm{~mm}$ carbon steel, strips with a cross-section $6 \times 21.5 \mathrm{~mm}$ carbon steel are inter welded between the tubes. The spacing between the tubes is $80 \mathrm{~mm}$. The front wall tubes up to the $12000 \mathrm{~mm}$ level are made of alloy steel. Furnace chamber bottom consists of the front wall tubes inclined to the horizontal plane with angle $15^{\circ}$. Rear wall of the upper part of the furnace forms aerodynamic projection or 'nose' of 2500mm depth [3].

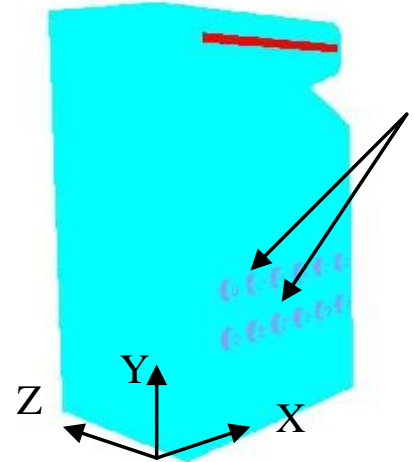

Figure 1. Furnace chamber

Burners

\subsection{Burners}

The furnace chamber is provided with 12 turbulent oil-gas burners, mounted on the rear wall in two stages. The burners of the lower stage are mounted at $6150 \mathrm{~mm}$ from the lower surface, the burners of the upper stage at $8750 \mathrm{~mm}$.

Burners are provided for separate gas and fuel oil burning. If the burner operates at reduced loads, the air canal is divided into the inner and peripheral sections to provide optimal air speed near the head of the fuel oil burner. In the inner and peripheral canals, air flows passes through swirl vanes before entering into the burner enclose. Swirling of the air flow in the inner canal is performed by the axial vanes. There are 18 fixed blades mounted at an angle to the burner axis. Air flow is swirled in the peripheral canal by 24 blades fixed at an angle $60^{\circ}$ to the radius.

Fuel gas is fired centrally via an annular gap between the central tube of $245 \times 8 \mathrm{~mm}$ diameter and a concentric tube of $325 \times 8 \mathrm{~mm}$ in diameter. From the furnace side, a quarl or truncated cone is fitted to the burner exhaust, provided with two series of nozzles, first series is eight apertures of $15 \mathrm{~mm}$ diameter, and the second is eight apertures of $22 \mathrm{~mm}$ diameter. Steam pressure-jet burner output is $4800 \mathrm{~kg} / \mathrm{h}$. The burner consists of the case header and reducer. Fuel oil passes through the control tube $(25 \times 3.5 \mathrm{~mm}$ in diameter $)$ of the case, then in the header through the filter, fuel oil swirler and oil nozzle [3].

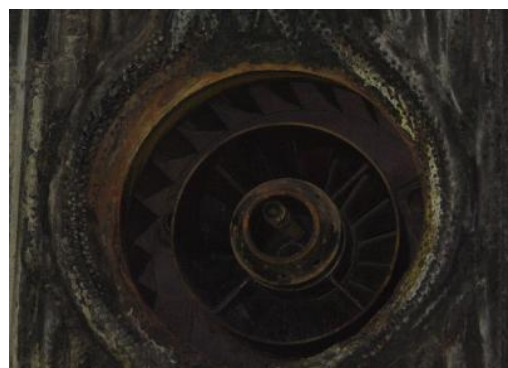

Figure 2. Burner inside furnace

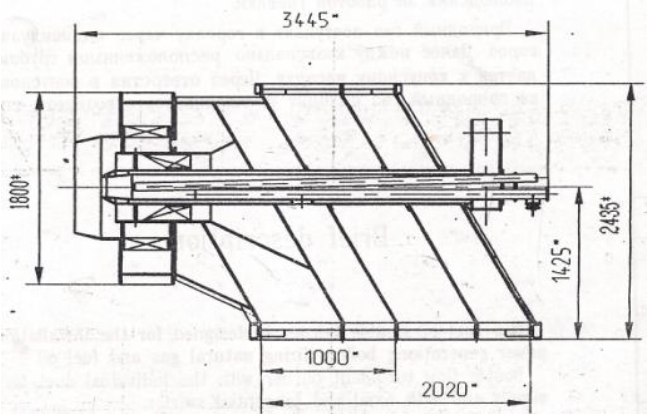

Figure 3. Schematic diagram of the burner [3] 


\section{THEORETICAL ANALYSIS}

The following equations must be considered in the analysis of flow and combustion in furnace:

3.1.Continuity equation

$\frac{\partial}{\partial z}(\rho U)+\frac{1}{r} \frac{\partial}{\partial r}(\rho r V)+\frac{1}{r} \frac{\partial}{\partial \theta}(\rho r W)=0$

\subsection{Equation of Motion (Momentum) $[15,16]$}

$\underline{\text { In } \mathrm{z} \text { - direction: }}$

$\frac{\partial}{\partial z}\left(\rho U U-\mu_{\text {eff }} \frac{\partial U}{\partial z}\right)+\frac{1}{r} \frac{\partial}{\partial r}\left(\rho r V U-\mu_{\text {eff }} r \frac{\partial U}{\partial r}\right)+\frac{1}{r} \frac{\partial}{\partial \theta}\left(\rho W U-\mu_{\text {eff }} \frac{1}{r} \frac{\partial U}{\partial \theta}\right)=$ source

Where:

source $=-\frac{\partial p}{\partial z}+\frac{\partial}{\partial z}\left(\mu_{\text {eff }} \frac{\partial U}{\partial z}\right)+\frac{1}{r} \frac{\partial}{\partial r}\left[r \mu_{e f f}\left(\frac{\partial V}{\partial z}\right)\right]+\frac{1}{r} \frac{\partial}{\partial \theta}\left[\mu_{e f f}\left(\frac{\partial W}{\partial z}\right)\right]$

In $\mathrm{r}$-direction:

$\frac{\partial}{\partial z}\left(\rho U V-\mu_{\text {eff }} \frac{\partial V}{\partial z}\right)+\frac{1}{r} \frac{\partial}{\partial r}\left(\rho r V V-\mu_{e f f} r \frac{\partial V}{\partial r}\right)+\frac{1}{r} \frac{\partial}{\partial \theta}\left(\rho W V-\mu_{e f f} \frac{1}{r} \frac{\partial V}{\partial \theta}\right)=$ source

Where:

source $=-\frac{\partial p}{\partial r}+\frac{\partial}{\partial z}\left[\mu_{e f f} \frac{\partial U}{\partial r}\right]+\frac{1}{r} \frac{\partial}{\partial r}\left[r \mu_{e f f} \frac{\partial V}{\partial r}\right]+\frac{1}{r} \frac{\partial}{\partial \theta}\left[\mu_{e f f}\left(r \frac{\partial\left(\frac{W}{r}\right)}{\partial r}\right)\right]+\rho \frac{W^{2}}{r}-\frac{2 \mu_{e f f}}{r}\left(\frac{1}{r} \frac{\partial W}{\partial \theta}+\frac{V}{r}\right)$

$\underline{\text { In } \Theta \text {-direction }}$

$$
\frac{\partial}{\partial z}\left(\rho U W-\mu_{e f f} \frac{\partial W}{\partial z}\right)+\frac{1}{r} \frac{\partial}{\partial r}\left(\rho r V W-\mu_{e f f} r \frac{\partial W}{\partial r}\right)+\frac{1}{r} \frac{\partial}{\partial \theta}\left(\rho W W-\mu_{e f f} \frac{1}{r} \frac{\partial W}{\partial \theta}\right)=\text { source }
$$

Where:

$$
\text { source }=-\frac{1}{r} \frac{\partial p}{\partial \theta}+\frac{\partial}{\partial z}\left[\mu_{e f f}\left(\frac{1}{r} \frac{\partial U}{\partial \theta}\right)\right]+\frac{1}{r} \frac{\partial}{\partial r}\left[\mu_{e f f}\left(\frac{\partial V}{\partial \theta}-W\right)\right]+\left[\frac{\mu_{e f f}}{r}\left(r \frac{\partial\left(\frac{W}{r}\right)}{\partial r}+\frac{1}{r} \frac{\partial V}{\partial \theta}\right)\right]-\frac{\rho W V}{r}+\frac{1}{r} \frac{\partial}{\partial \theta}\left[\mu_{e f f}\left(\frac{1}{r} \frac{\partial W}{\partial \theta}+\frac{2 V}{r}\right)\right]
$$

\subsection{Equation of Energy}

Where $\mathrm{c}_{\mathrm{p}}$ is assumed constant, then:

$\frac{\partial}{\partial z}\left(\rho U T-\frac{\lambda}{C_{p}} \frac{\partial T}{\partial z}\right)+\frac{1}{r} \frac{\partial}{\partial r}\left(\rho r V T-\frac{\lambda}{C_{p}} \frac{\partial T}{\partial r}\right)+\frac{1}{r} \frac{\partial}{\partial \theta}\left(\rho W T-\frac{\lambda}{C_{p}} \frac{1}{r} \frac{\partial T}{\partial \theta}\right)=$ source

where:

$$
\text { source }=\frac{q_{c . v .}}{C_{p}}=\frac{\dot{m}_{f} H_{c . v .}}{\text { volume }_{p}}
$$

\subsection{Boundary Conditions}

The general elliptic differential equation must be solved after the boundary conditions of the whole domain are applied with permissible and satisfied values with the following procedure:

\subsubsection{Inlet boundary conditions}

The properties of the fluid entering the boiler are known, such as temperature, viscosity, density, velocity.

Volume flow rate of oil input to one unit $F=24.61 \operatorname{Exp}(0.0041 \mathrm{~N})$ [11]

This is and empirical formula provided by the manufacturer.

Where: $\mathrm{N}$ is the load of the unit in Megawatts.

For one burner, oil flow rate $=\frac{F}{12}$ because there are 12 burners in one unit.

$\therefore V_{\text {oil }}=\frac{\dot{m}}{\rho \cdot a}$

Where: $\mathrm{V}_{\mathrm{oil}}$ : the reference oil fuel velocity $(\mathrm{m} / \mathrm{s})$

$\rho:$ fuel density $\left(\mathrm{kg} / \mathrm{m}^{3}\right)$

a: nozzle area $\left(\mathrm{m}^{2}\right)$

Air flow rate for one burner $=(107590 \operatorname{Exp}(0.0111 \mathrm{~N})) / 12$ [11] 


\subsubsection{Symmetry line in front of burner}

The boundary conditions for variables must be considered, including gradients $\partial \phi / \partial r$. Maximum temperatures allowed are $2020^{\circ} \mathrm{C}$ for crude oil, and equal $1879^{\circ} \mathrm{C}$ for gaseous fuel [11].

\subsubsection{Velocity}

All velocity components at the furnace walls must be equal to zero (no slip conditions).

\subsubsection{Properties conditions}

The temperature of the wall is set at $541^{\circ} \mathrm{C}$; this is higher than the temperature of steam in the boiler and reflects heat transfer processes from the boiler/furnace to the steam. The other properties are derived internally via mathematical relations (density, enthalpy ...etc.).

\section{COMBUSTION AND CHEMICAL REACTIONS}

The combination of the combustible fuel elements and compounds in the fuel with all the oxygen requires temperatures high enough to ignite the constituents, mixing or turbulence to provide intimate oxygen-fuel contact, and sufficient time to complete the process [17].

Table 1 Combustion process analysis

Gaseous fuel analysis via the south oil Refinery Company is Methane (density CH4 $=0.6679 \mathrm{~kg} / \mathrm{m}^{3}$ )

Where $\mathrm{M}_{\mathrm{O} 2}, \mathrm{M}_{\mathrm{C}}, \mathrm{M}_{\mathrm{H} 2}, \mathrm{M}_{\mathrm{S}}, \mathrm{M}_{\mathrm{CO} 2}, \mathrm{M}_{\mathrm{H} 2 \mathrm{O}}$ and $\mathrm{M}_{\mathrm{SO} 2}$ are the molecular weight of oxygen, carbon, Hydrogen, sulfur, carbon dioxide, water and sulfur dioxide, neglecting the ash value because it does not enter the reaction process, i.e. from the above table:-

The total mass of oxygen required per kg of fuel:

\begin{tabular}{|l|l|l|c|c|c|}
\hline $\begin{array}{l}\text { Products per } \\
\text { oxidant }\end{array}$ & $\begin{array}{l}\text { Theoretical O2 } \\
\text { required per kg of } \\
\text { fuel }\end{array}$ & $\begin{array}{l}\text { Reaction } \\
\text { by weight } \%\end{array}$ & $\begin{array}{l}\text { Fuel } \\
\text { constituent }\end{array}$ & No \\
\hline $\mathrm{CO}_{2}=\mathrm{C} \% \times \frac{M_{\mathrm{CO} 2}}{M_{C}}$ & $C \% \times \frac{M_{O 2}}{M_{C}}$ & $\mathrm{C}+\mathrm{O} 2 \longrightarrow \mathrm{CO} 2$ & 0.865 & $\mathrm{C}$ & 1 \\
\hline $\mathrm{H}_{2} \mathrm{O}=H \% \times \frac{M_{H 2 O}}{2 M_{H}}$ & $H \% \times \frac{M_{O 2}}{M_{H 2}}$ & $2 \mathrm{H} 2+\mathrm{O} 2 \longrightarrow \mathrm{H} 2 \mathrm{O}$ & 0.11199 & $\mathrm{H}$ & 2 \\
\hline
\end{tabular}

$\left(\mathrm{m}_{\mathrm{OX}}\right)=C \% \times \frac{M_{O 2}}{M_{C}}+H \% \times \frac{M_{O 2}}{M_{H 2}}+S \% \times \frac{M_{O 2}}{M_{S}}$

But the concentration of oxygen in air is 23.36 by weight, then;

the exact weight of air required for combustion per $\mathrm{kg}$ of the fuel $=\frac{m_{o x}}{0.2314}$

Most gases involved in combustion calculations can be approximated as ideal gases, the reacting substances can be modeled by the equation of state [18].

$\rho_{\text {mix }}=\frac{p / \bar{R} T}{\left(\frac{m_{f}}{M_{f}}+\frac{m_{o x}}{M_{O X}}+\frac{m_{p r}}{M_{p r}}\right)}$

Where:

$\mathrm{m}_{\mathrm{pr}}=\mathrm{m}_{\mathrm{CO} 2}+\mathrm{m}_{\mathrm{H} 2 \mathrm{O}}+\mathrm{m}_{\mathrm{SO} 2}$

$\rho_{\mathrm{CO} 2}=\frac{p_{\mathrm{CO} 2} / \bar{R} T}{m_{\mathrm{CO} 2} / M_{\mathrm{CO} 2}}$

$\rho_{\mathrm{H}_{2} \mathrm{O}}=\frac{p_{\mathrm{H} 2 \mathrm{O}} / \bar{R} T}{m_{\mathrm{H} 2 \mathrm{O}} / M_{\mathrm{H} 2 \mathrm{O}}}$

$\rho_{\mathrm{SO}_{2}}=\frac{p_{\mathrm{SO} 2} / \bar{R} T}{m_{\mathrm{SO} 2} / M_{S O 2}}$ 


\section{RADIATION AND HEAT BALANCE}

After combustion of fuel inside the furnace, heat must be radiated from the flame to all walls of furnace, then by the first law of thermodynamics:

Heat released by burning fuel $=$ Heat absorbed by air + Heat radiated to all inside faces of the furnace

$Q=m_{a} C_{p}\left(T_{f}-T_{a}\right)+\varepsilon \sigma A_{p}\left(T_{f}{ }^{4}-T_{a}{ }^{4}\right)$

Where

$\mathrm{Q}=$ mass $\times$ calorific value of fuel $(\mathrm{kJ} / \mathrm{s})$

VI. CALCULATIONS AND INPUTS

Table2 Gaseous fuel input one burner (unit load 210MW)

\begin{tabular}{|l|l|l|l|}
\hline $\begin{array}{l}\text { Gas } \\
\text { entrance } \\
\text { area }\left(\mathrm{m}^{2}\right)\end{array}$ & $\begin{array}{l}\text { Mass } \\
\text { flow rate } \\
(\mathrm{kg} / \mathrm{s})\end{array}$ & $\begin{array}{l}\text { Gas } \\
\text { velocity } \\
(\mathrm{m} / \mathrm{s})\end{array}$ & $\begin{array}{l}\text { Gas } \\
\text { temperature } \\
\text { input }(\mathrm{K})\end{array}$ \\
\hline 0.033535 & 0.75757 & 33.823 & 300 \\
\hline
\end{tabular}

Table3 Hydraulic diameters $(\mathrm{m})$

\begin{tabular}{|lr|l|l|l|l|}
\hline $\begin{array}{l}\text { Central air } \\
\text { inlet }\end{array}$ & $\begin{array}{l}\text { Tangential } \\
\text { air inlet }\end{array}$ & Pressure outlet & $\begin{array}{l}\text { Recirculation } \\
\text { flue gas vents }\end{array}$ & Gas fuel inlet \\
\hline $\begin{array}{l}2\left(\mathrm{r}_{\mathrm{o}}-\mathrm{r}_{\mathrm{i}}\right) \\
0.25125\end{array}$ & 0.29 & $\frac{2 a b}{(a+b)}=0.9111$ & 1.92 & 0.14158 \\
& & & & \\
\hline
\end{tabular}

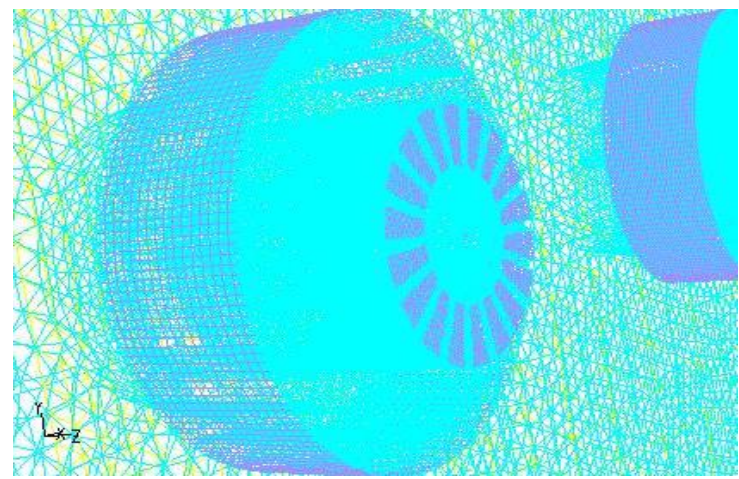

Figure 4. Burners with furnace

Table4 Flue recirculated gases (at gaseous fuel firing)

\begin{tabular}{|c|c|c|c|c|}
\hline $\begin{array}{c}\text { Velocity at } \\
\text { load } 210 \mathrm{MW} \\
(\mathrm{m} / \mathrm{s})\end{array}$ & $\begin{array}{c}\text { Velocity at } \\
\text { load 140MW } \\
(\mathrm{m} / \mathrm{s})\end{array}$ & $\begin{array}{c}\text { Velocity at } \\
\text { load 70MW } \\
(\mathrm{m} / \mathrm{s})\end{array}$ & $\begin{array}{c}\text { Total 16 } \\
\text { ducts area } \\
(\mathrm{m} 2)\end{array}$ & $\begin{array}{c}\text { Temperature } \\
(\mathrm{K})\end{array}$ \\
\hline 0.0072 & 0.0164 & 0.0098 & 1.44 & 578 \\
\hline
\end{tabular}

Air flow rate $=107590 \operatorname{Exp}(0.0111 \mathrm{~N})$

The stoichiometric ratio for methane $=0.058$, by weight.

Rich flammability limit must greater than 10\%-50\% from the stoichiometric fraction; therefore a value of 0.064 is used in PDF table creation. In this study, load 210MW, Non-Premixed method, Non-recirculated flue gases with FLUENT6.3.26 [20] and GAMBIT2.3.16 package is used to analyze compositions and results.

VII. RESULTS AND DISCUSSION

The results of this study were found to give predictions in line with the literature review of gas movement and aerodynamics inside the furnace together with all other thermal, concentrations of species and products of combustion. This work is done by using gaseous fuel (methane $\mathrm{CH} 4$ ) at the full load of the power unit $(210 \mathrm{MW})$, the recirculation of flue gases was stopped because at this point, there was no benefit to use flue gases to decrease NOx. 


\subsection{Aerodynamics prediction}

Figure 5 indicates the velocity vectors inside the furnace at vertical side planes $(X=1.3,2.6,3.88)$. Other work in a similar furnace of $350 \mathrm{MW}$ capacity produced velocities up to $120 \mathrm{~m} / \mathrm{s}$ [21]. Here velocities reach $85.2 \mathrm{~m} / \mathrm{s}$ close to the burners at $X=1.3 \mathrm{~m}$, there are two vortex zones formed in the upper and lower parts of the furnace as found by Sobolev et.al. [13]. This is because with two levels of burners, the lower burner affects the aerodynamics of lower part of furnace (Lower vortex) and the upper burner affects the upper part of furnace (upper part). Also the furnace design creates an aerodynamic projection $2.5 \mathrm{~m}$ deep at levels $17 \mathrm{~m}$ to $20.5 \mathrm{~m}$ that throttles the flue gases at level $19.5 \mathrm{~m}$, leading to high convection heat transfer gain especially at platen super heater in the upper ceiling of furnace.

At the side plane of $X=1.3 \mathrm{~m}$ the maximum velocity magnitude is $68 \mathrm{~m} / \mathrm{s}$ closed to outlet vent of the furnace but this value is limited between 15 to $23 \mathrm{~m} / \mathrm{s}$ closed to the burners and in the upper half section in front of the upper burners towards the outlet vent. The dominant velocity in this section is in the range ( 7 to $23 \mathrm{~m} / \mathrm{s}$ ).

At section $\mathrm{X}=2.6 \mathrm{~m}$ high velocities, up to $85 \mathrm{~m} / \mathrm{s}$, are found close to the burners but the maximum velocity is at the outlet vent, the dominant velocity of gases inside furnace at this plane is 7 to $23 \mathrm{~m} / \mathrm{s}$.

Worthy of observation is the fact that the dominant velocity of section $X=1.3 \mathrm{~m}$ is more than that for $\mathrm{X}=2.6 \mathrm{~m}$ because of the divergent quarl exit of the burner forces the gases into this section as shown by the velocity vectors. At section plane $X=3.88 \mathrm{~m}$ the same level of velocities as in section $X=2.6 \mathrm{~m}$ is found, because of its location between two planes of burners $(X=2.6,5.16 \mathrm{~m})$. However there is a weak velocity plane just lying between the upper and lower burners in this section of the furnace. The dominant level of velocity magnitude is between 8 and $23 \mathrm{~m} / \mathrm{s}$.

Moving onto the same section for the plane $\mathrm{X}=5.16 \mathrm{~m}$ in figure 7 , there is now a weak velocity range extending between the bottom corner of the furnace to the flue gases recirculation vents at the front wall containing the vortex in the lower part of furnace.

The section $\mathrm{X}=6.44 \mathrm{~m}$ produces similar results to that at $\mathrm{X}=3.88 \mathrm{~m}$ but the difference is that the dominant velocity magnitude in this section is lower than for $\mathrm{X}=3.88 \mathrm{~m}$ that is because of high fluctuation of velocity inside the furnace in the region of the plane of symmetry.

Thus, the section $X=7.72 \mathrm{~m}$ is similar to $X=5.16 \mathrm{~m}$ but with low velocity range.

The differences between similar planes above are due to:

(1) The reverse direction of swirling flow of air and fuel passing from burners to furnace, the clockwise flow direction for burner number 1 , (found at the point $(2.6,6.15,0)$ in the domain). This is in reverse direction with respect to neighbouring burners (number 2 at point $(5.16,6.15,0)$ and number 4 at point $(2.6,8.75,0)$ ). This is to create a series of burners that are 'in mesh' and do not create unstable flows between the burners. Both central vanes (radial) and tangential vanes of individual burners act in the same direction.

(2) The fluctuation of the flow because of mutual burner interaction.

From figure 5 and 6 , it is seen that there are steep velocity gradients at the corners of the furnace because of separation and generation of corner vortices.

Figure 7 shows the three velocity components "radial, tangential and axial velocity" at section $X=2.6 \mathrm{~m}$. Radial velocities are as expected being limited to between 73.9 to $-82.8 \mathrm{~m} / \mathrm{s}$, low radial velocity values occur at the burner entrance because the axial and tangential velocity components are dominated here but in the other places inside the furnace the dominant value of radial velocity is between 3.37 to $26.9 \mathrm{~m} / \mathrm{s}$. Tangential velocity is typically -8.14 to $18.9 \mathrm{~m} / \mathrm{s}$, reaching its maxima at the furnace entrance closed to the burners at $66.4 \mathrm{~m} / \mathrm{s}$. With the axial velocities the dominant direction is negative because the direction of the $\mathrm{z}$ axis is negative in the direction of the mixture flow at the burner typical values are limited to between -4.19 to $18.6 \mathrm{~m} / \mathrm{s}$ with maximum value at the outlet vent of $152 \mathrm{~m} / \mathrm{s}$.

Figure 8 showing centerline axial velocities, illustrates similar trends to the previous studies of Sislian et.al. [9] and Azazi [11].

Figure 9 shows the velocity components at horizontal plane $\mathrm{Y}=8.75 \mathrm{~m}$, with dominant values 23.2 to $54.2 \mathrm{~m} / \mathrm{s}$ with low velocity values at front and side wall. The figure also illustrates the 'crowding effect' of the burners where the centre flow is squeezed by the outer two.

Figure 10 indicates the velocity vectors at horizontal planes $\mathrm{Y}=22.5 \mathrm{~m}$, and $\mathrm{Y}=22 \mathrm{~m}$ (furnace outlet) for gaseous fuel. The directions of vectors towards the outlet vent of furnace are shown here with high values at the vent.

\subsection{Turbulent kinetic energy}

Figure $11 \mathrm{~A}$ denotes the turbulent kinetic energy at level $\mathrm{X}=2.6 \mathrm{~m}$, the figure gives prediction for these values inside the furnace, the maximum value is at outlet vent and near the burners after the combustion process, the other dominated values are equal and lower than $24 \mathrm{~m}^{2} / \mathrm{s}^{2}$. Largest values are closest to the burners as to be expected. 
Figure 11B shows a comparison with the previous studies of Sislian et.al. [9] and Azazi [11]. Closest similarities are to the work of Azazi.

\subsection{Temperature}

Figure 12A and Fig.12B shows the static temperature distribution in the zone of interest. Maximum temperatures lie at the centre of furnace towards the wall of the burners. Burnout takes little considerable time, causing the highest temperature regions of the flame to be located near to the wall of burners. The upwards lobe of hot gas at the opposite wall shown at section $\mathrm{X}=2.6 \mathrm{~m}$ is caused by the natural upwards motion of the gases as they leave the burner.

Figure 13 shows a horizontal section of temperatures for $Y=6.15 \mathrm{~m}$, burner interactions are clearly visible.

Figure 14 compares the previous studies of Azazi [11] with this work of liquid and gaseous fuel, again Azazi's work most closely correlates [22].

\subsection{Pollutant NOx}

Figure 15 shows NOx distributions and its part per millions inside the furnace chamber. $\mathrm{NO}_{\mathrm{x}}$ levels gradually build up away from the burners with highest values being produced in the lower part of furnace and close to the opposite walls. Thus the flue gas recirculation vents are placed here. Maximum values of NOx are predicted at the back part of the symmetry plane $\left(6.53 \times 10^{-4}\right)$, in accord with other measurements and predictions.

The formation of NOx can be attributed to four distinct chemical kinetic processes: thermal NOx formation, prompt NOx formation, fuel NOx formation, and intermediate N2O. Thermal NOx is formed by the oxidation of atmospheric nitrogen present in the combustion air. Prompt NOx is produced by high-speed reactions at the flame front, and fuel NOx is produced by oxidation of nitrogen contained in the fuel. At elevated pressures and oxygen-rich conditions, NOx may also be formed from molecular nitrogen (N2) via N2O. The reburning reduces the total NOx formation by making the NO react with hydrocarbons and ammonia, respectively [20]. Figure 16 shows the thermal $\mathrm{NO}_{\mathrm{x}}$ which is the main contributor to the overall NOx levels.

\subsection{Properties}

Figure 17 shows the static pressure of the entire domain, the working pressure lying between 2300 to $2560 \mathrm{~Pa}$ gauge. This pressure increases from the burner inlet (2340 pa) to the exhaust (2530 pa) as in figure 18A.

Figure 18B gives comparison with the work of Azazi [11] and is broadly in line. It also satisfies the manufacturer ANSALDO's catalogue [22] with pressure range between 4454 pa to 2324 Pa gauge for gas pressure at the boiler and between 4100 pa to $2158 \mathrm{~Pa}$ gauge for oil pressure. The fluctuation of pressure is very small in contrast with temperature and velocity.

Figure 19A shows the configuration of the burner from $t$ inside of the furnace with peripheral vents of gaseous fuel clearly visible [13].

Figure 19B shows contours of mass fraction for NO of Sobolev et.al [13] for a similar burner from a similar Russian Power station fired on natural gas. The similarities with this study are clear.

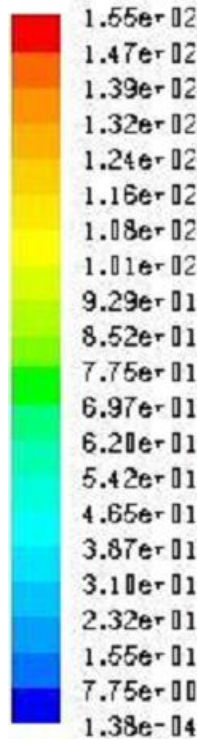

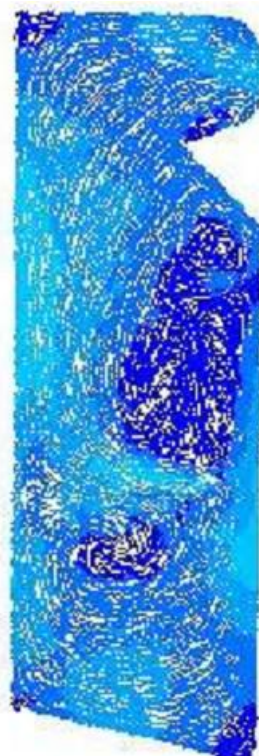

$\mathrm{X}=1.3 \mathrm{~m}$

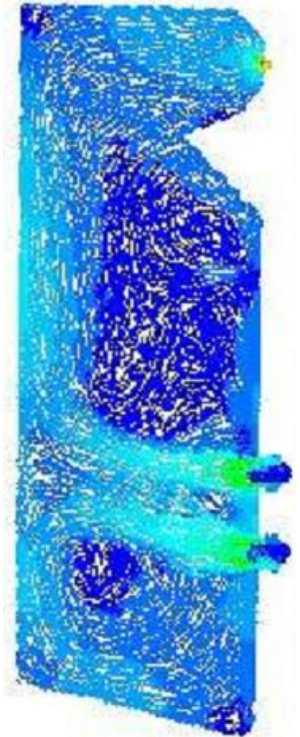

$\mathrm{X}=2.6 \mathrm{~m}$

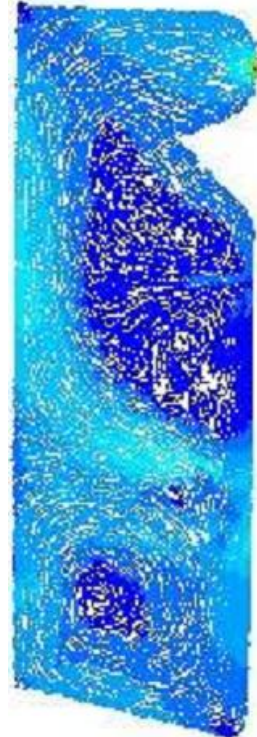

$\mathrm{X}=3.88 \mathrm{~m}$ 
Figure 5. Velocity vectors at vertical side planes

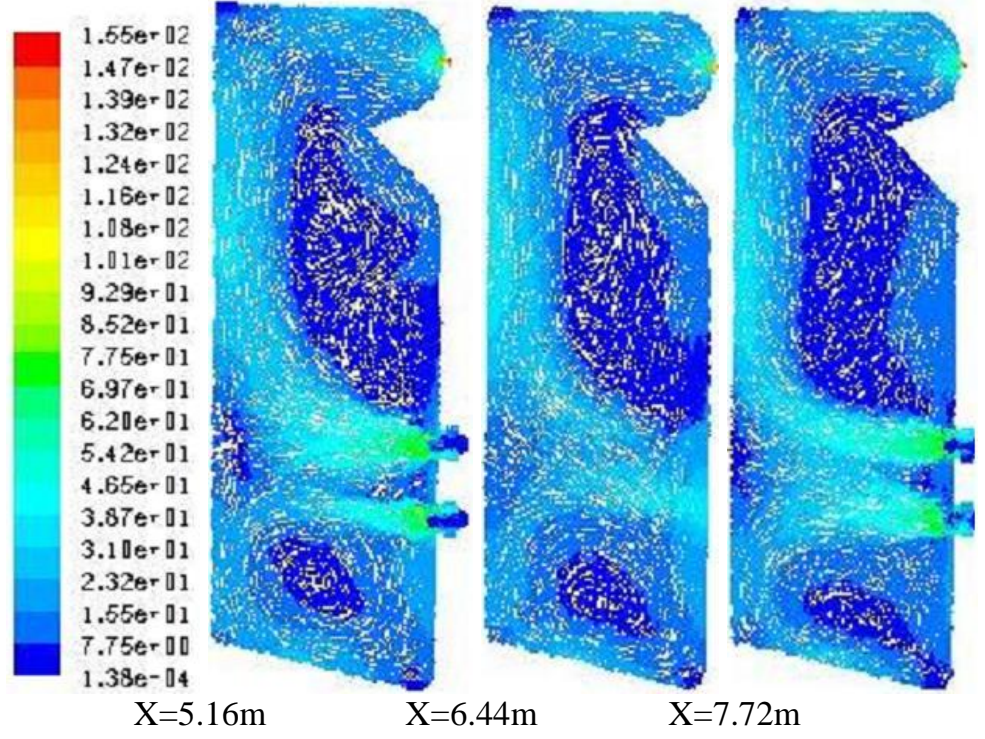

Figure 6. Velocity vectors at vertical side planes

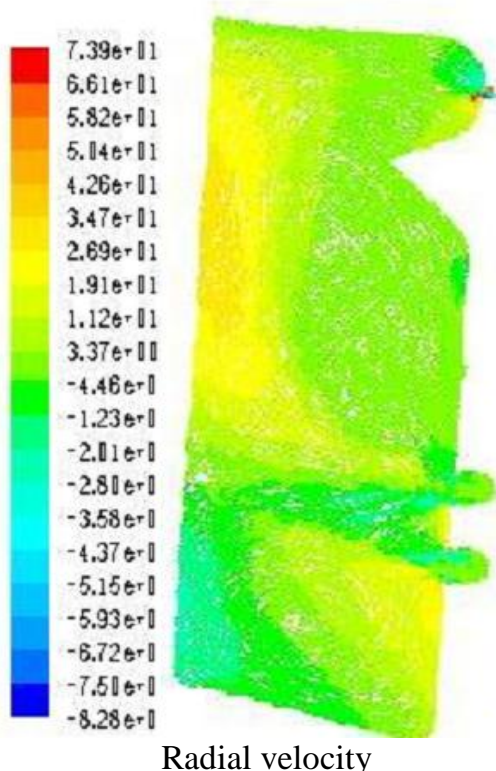

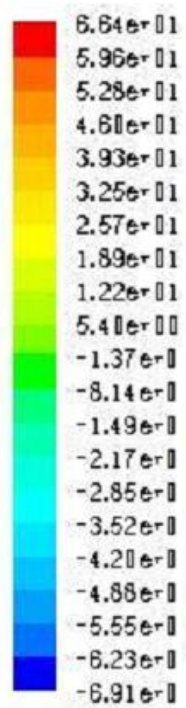

Tangential velocity

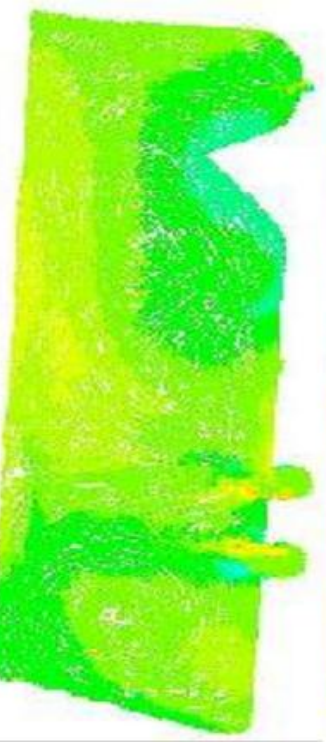

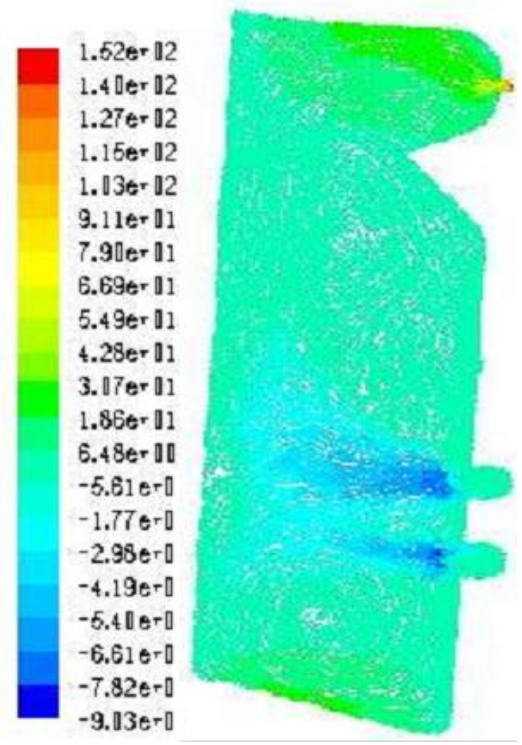

Axial velocity

Figure 7. Velocity components at $X=2.6 \mathrm{~m}$

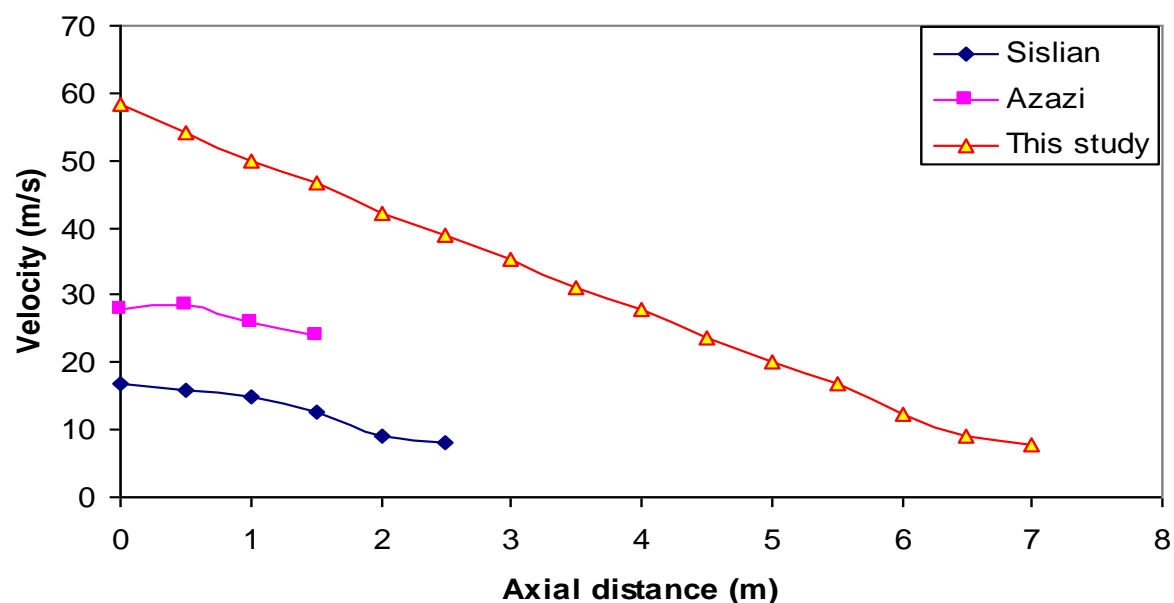

Figure 8. Axial Velocity with flame 

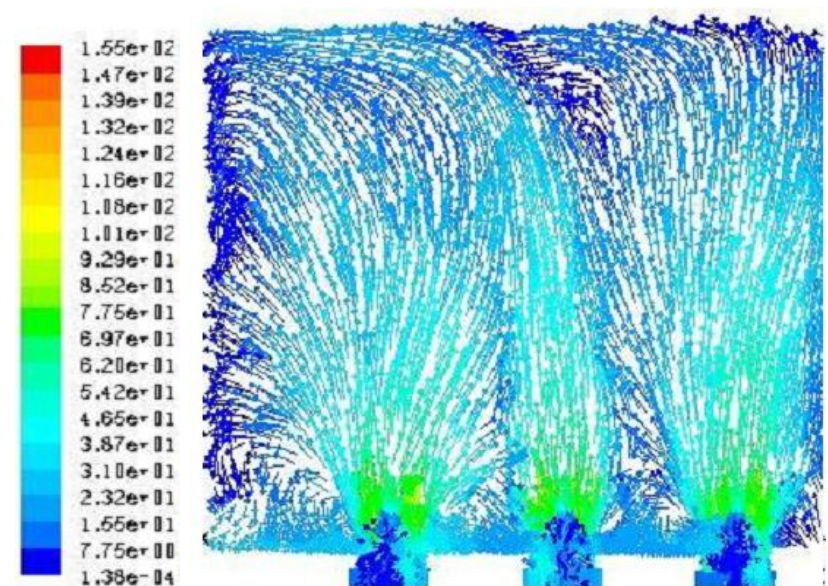

Figure 9. Velocity vectors at plane $\mathrm{Y}=8.75 \mathrm{~m}$
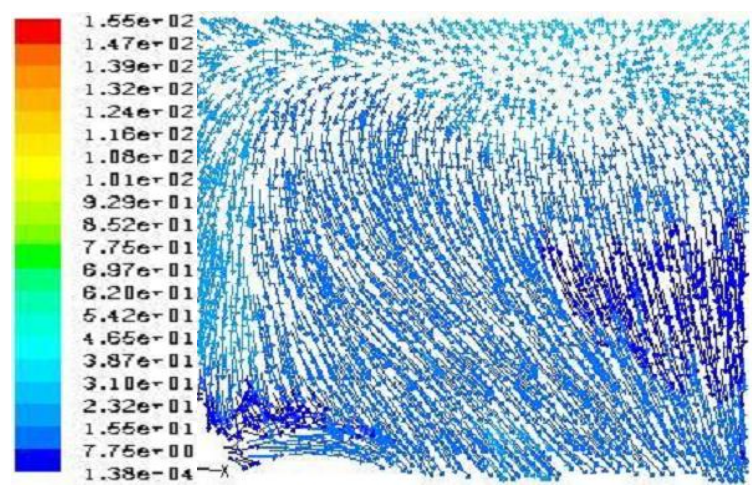

A

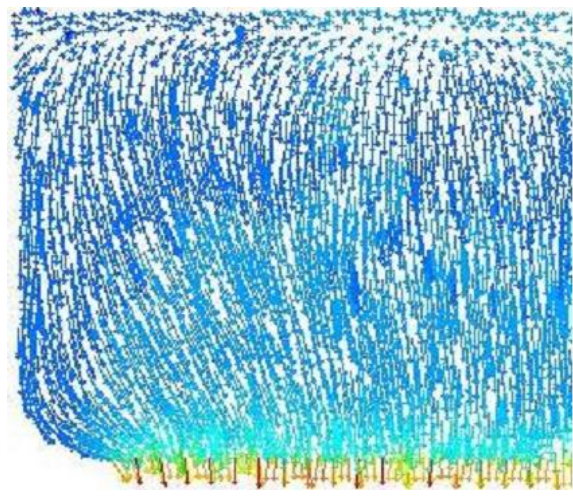

$\mathrm{B}$

Figure 10. Velocity vectors at planes $\mathrm{Y}=20.5 \mathrm{~m}$ and $\mathrm{Y}=22 \mathrm{~m}$ (outlet)

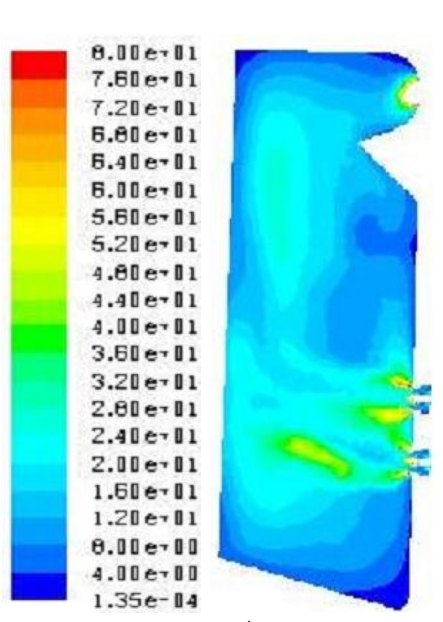

A

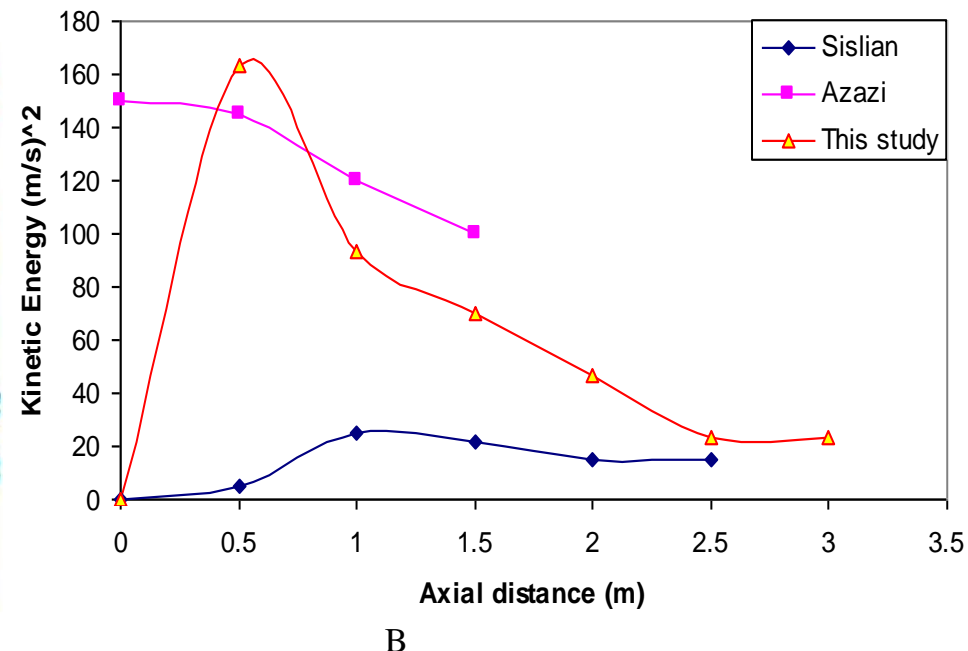

Figure 11. Turbulent kinetic energy A: at section $X=2.6 \mathrm{~m}, \mathrm{~B}$ : comparison curves 

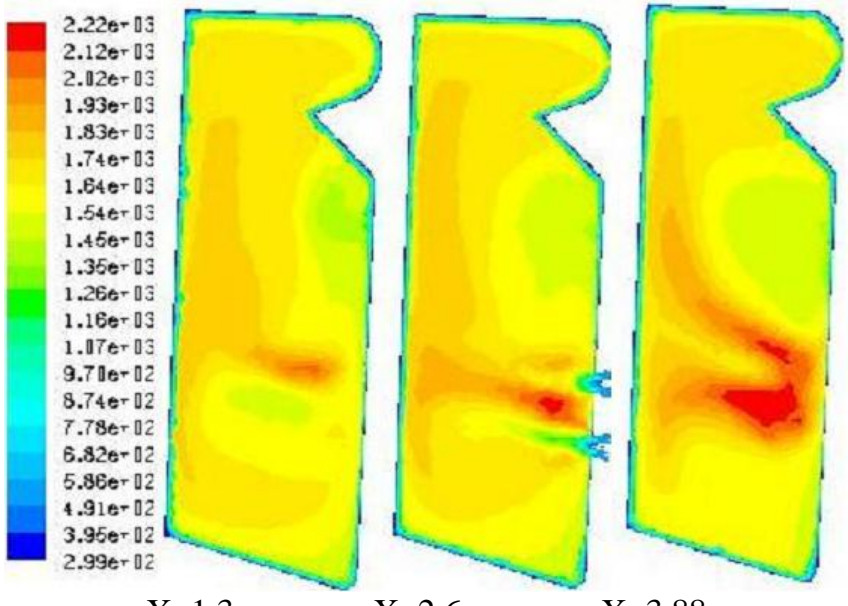

$$
\mathrm{X}=1.3 \mathrm{~m} \quad \mathrm{X}=2.6 \mathrm{~m} \quad \mathrm{X}=3.88 \mathrm{~m}
$$

Figure 12 A. Contours of static temperature at vertical side planes
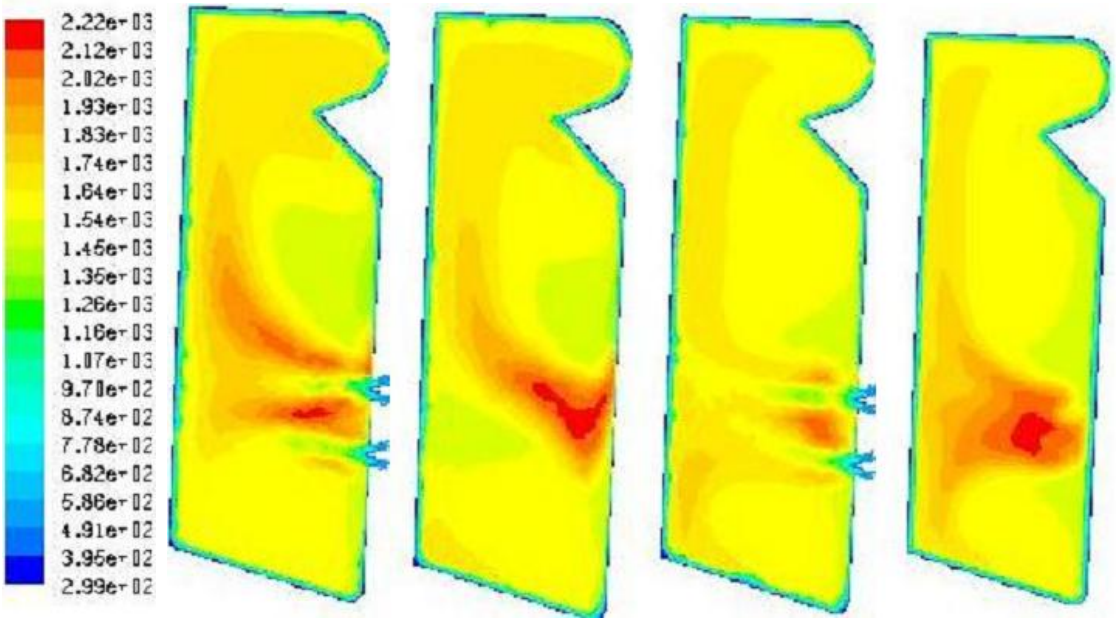

$$
\mathrm{X}=5.16 \mathrm{~m} \quad \mathrm{X}=6.44 \mathrm{~m}
$$

$\mathrm{X}=7.72 \mathrm{~m}$

$\mathrm{X}=9 \mathrm{~m}$

Figure 12 B. Contours of static temperature at vertical side planes

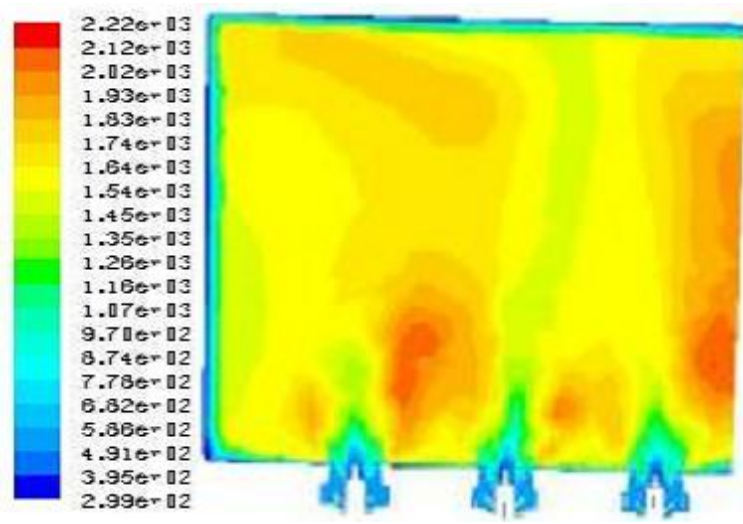

Figure 13. Contours of static temperature at horizontal plane $Y=6.15 \mathrm{~m}$ 


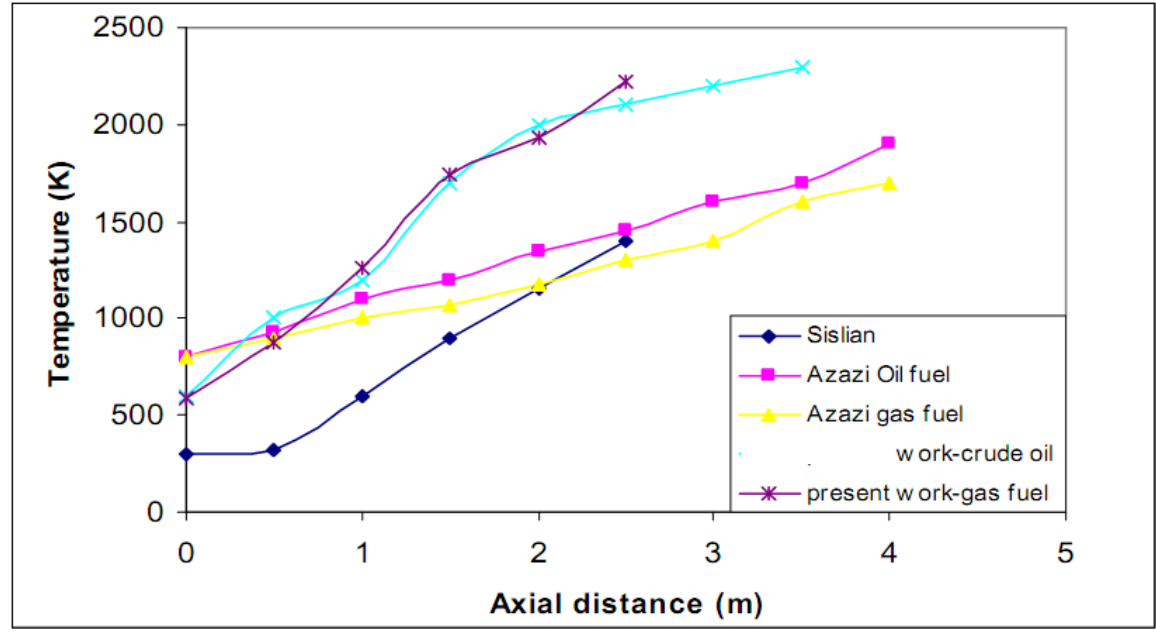

Figure 14. Static temperature of furnace chamber
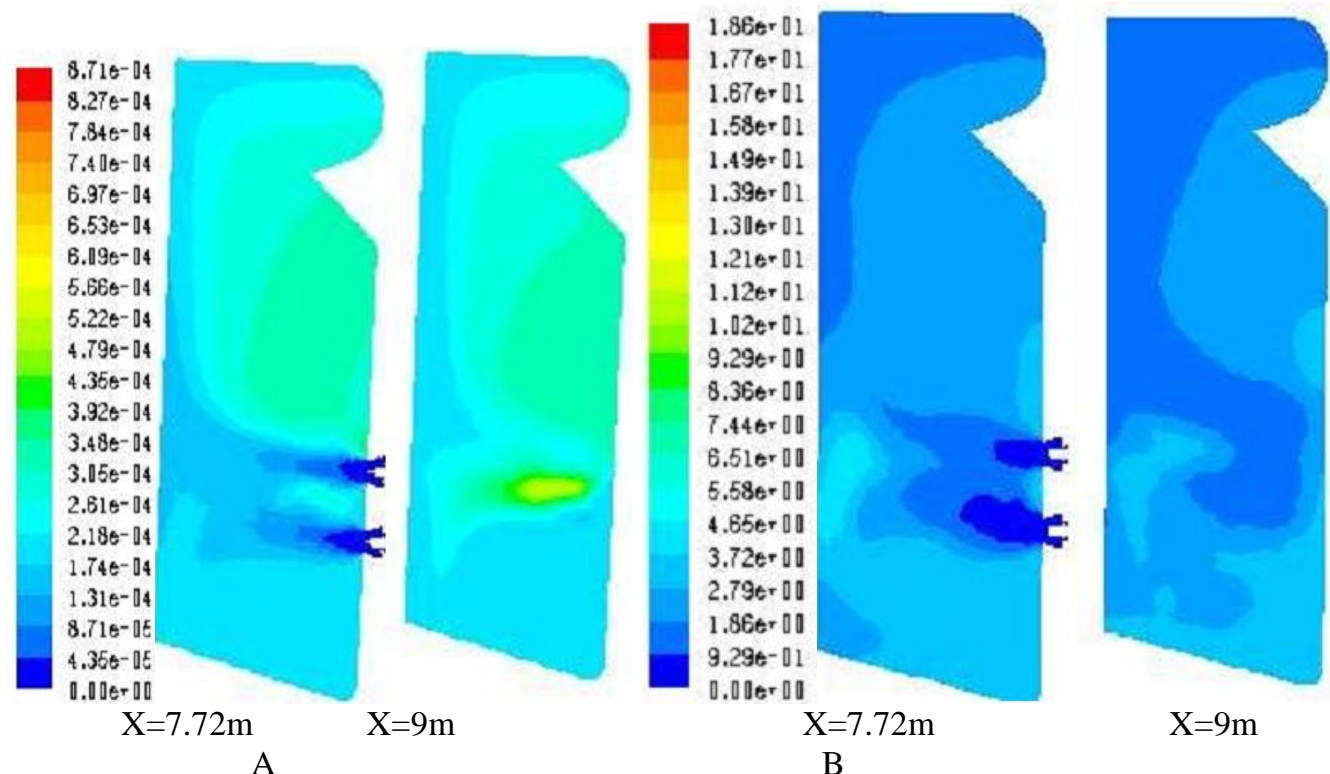

A

Figure 15. Contours of A: total pollutant of NOx, B: NOx ppm (part per million)

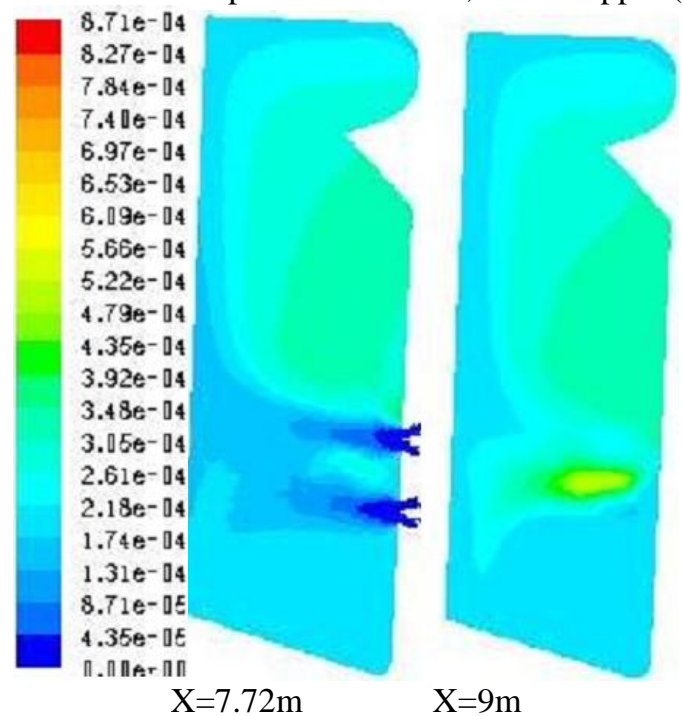

Figure 16. Contours of thermal NOx 


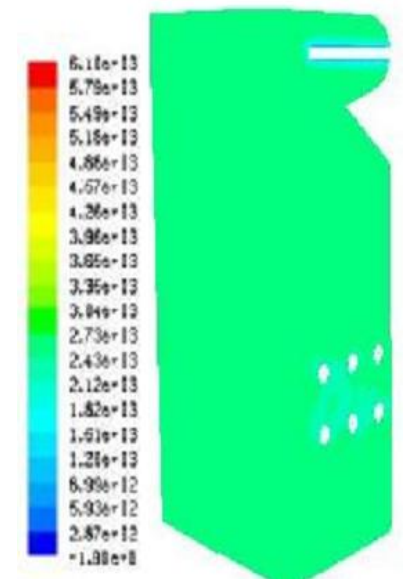

Figure 17. Contours of static pressure (Pascal) for domain

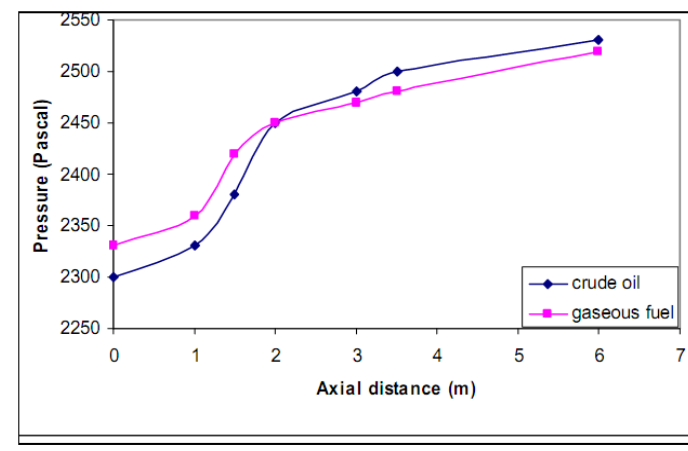

A

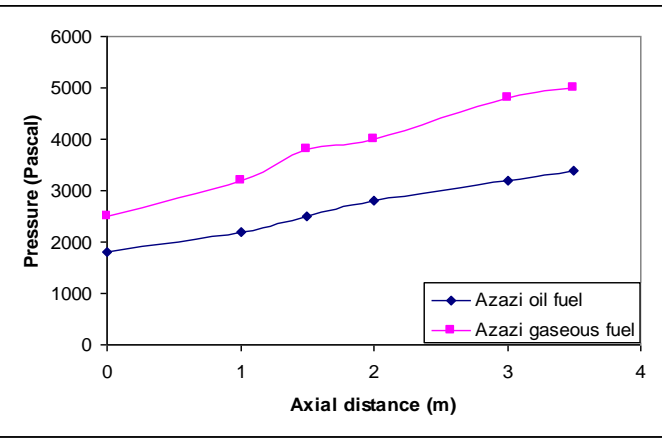

B

Figure18. Static pressure (Pascal) for A: domain, B: Azazi study [11]

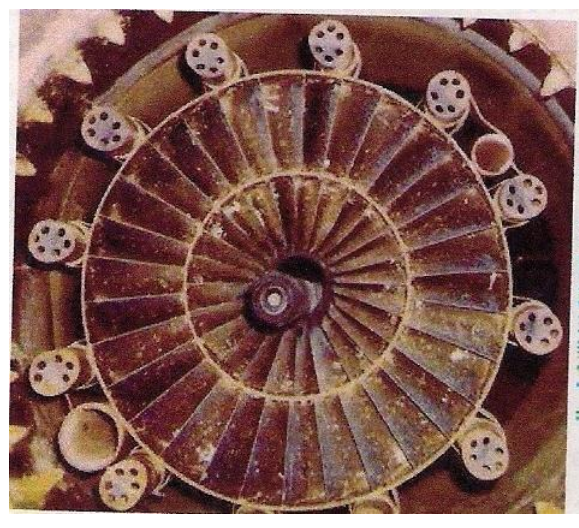

A

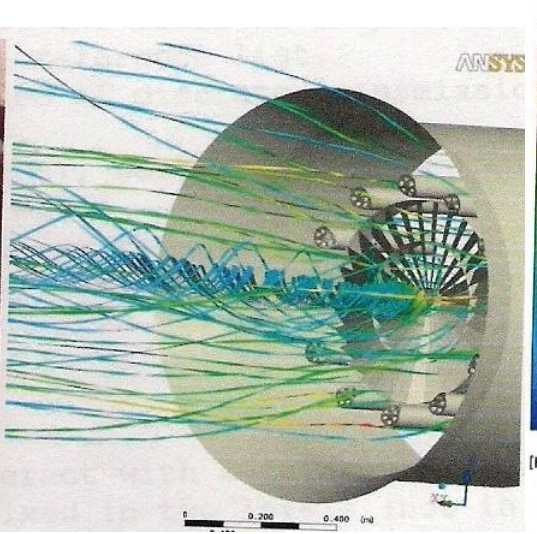

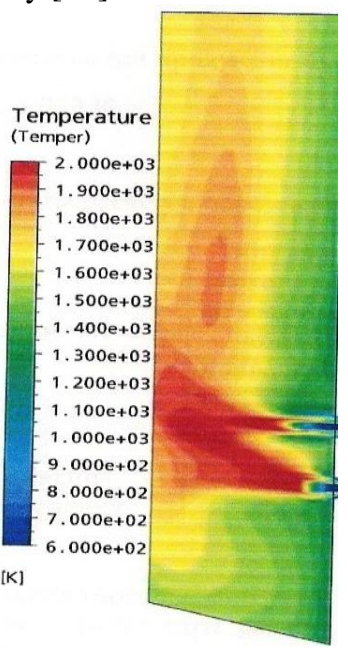

B

Figure 19. Sobolev et.al.[13] A. Burner, B. contour of temperature

VIII.

CONCLUSIONS

According to the FLUENT predictions, the following may be concluded:

1- Maximum NOx for gaseous fuel is concentrated at the line of symmetry of the furnace ( $\mathrm{X}=9 \mathrm{~m})$ close to the back wall of furnace, because of the high temperatures gradient and low velocities, this is the reason for operating the flue gases recirculation at this position.

2- There are two vortices happened in the lower and upper parts of the furnace chamber.

3- The maximum temperature inside the furnace chamber lies in the burner plane, but at the centre plane, due to the time required to burn out the gaseous fuel is few. Burning natural gas will clearly produce much higher temperatures close to the burner as it reacts much faster.

4- Velocity magnitude increases with increasing load as to be expected. 
5- The recirculation of flue gases is very important as it serves to push the region of maximum temperature away from the wall and at the same time lessen production of NOx.

6- The static pressure gradient increased with increasing the load, as to be expected.

7- The turbulent kinetic energy of burned gases increased with increased load due to the higher velocities.

8- The maximum NOx emissions are at a load of 70MW gradually decreasing with increasing the load to minimum value at maximum load $(210 \mathrm{MW})$, this is the reason of operating the flue gases recirculation at load 70MW whilst stopping it at load of 200-210MW.

\section{REFERENCES}

[1] Jones W.P , PhD Thesis, Imperial College London University, UK, 1971.

[2] Gupta.A.K., Lilley D.G, Syerd N., "Swirl Flows", first edition Abacus press, UK, 1984.

[3] Technoprom Company instruction Manual for Nassiriya power plant, 1979.

[4] Beer J.M. and Chigier N.A., "Combustion Aerodynamics", Applied Science, London, UK, 1972.

[5] Syred N. and Beer J.M., "Combustion on swirling flows: A review ", Combustion and Flame, vol. 23, pp.143-201, 1974.

[6] Kilik E., "The influence of Swirler Design Parameters on the Aerodynamics of the Downstream Recirculation Region", Ph.D. thesis, school of Mechanical Engineering, Cranfield Institute of Technology, England, 1976.

[7] Najim S.E., "An Aerodynamics Study of Cyclonic Combustion with Gaseous Fuels “, Ph.D. Thesis , Mech. Eng. and Energy Studies Dept., Cardiff University, UK, 1979.

[8] Arscott J.A., Chew P.E. and Lawn C.J., "Improvement in combustion Efficiency Through the Matching of Air and Fuel on an oil Fired Boiler “, Journal of Institute of Energy ,LIII, vol. 3, no 2, pp. 3-15, 1980.

[9] Sislian J.P., Jiang L.Y. and Cusworth R.A., "Laser Doppler Velocimetry Investigation of the Turbulence Structure of Axisymmetric Diffusion Flames", Progress in Energy and Combustion Science, vol.14, no.2, pp.99-146, 2000.

[10] Cheng R.K., Yegian D.T., Meyasato M.M., Samuelsen G.S., Benson C.E., Pellizzar R. and Loftus P., "Proceedings of the Combustion Institute", vol. 28 ,pp. 1305-1313, 2000.

[11] Azazi F.A., "Aerodynamics and Thermal Prediction of Al-Hartha Power Generation Plant Furnace", $\mathrm{Ph} . \mathrm{D}$. Thesis, College of Engineering, Basra University, Iraq, 2001.

[12] Nemoda S., Bakic V., Oka S., Zivkovic G. and Crnomarkovic N., "Experimental and Numerical investigation of gaseous fuel combustion in swirl chamber", International Journal of Heat and Mass Transfer, vol.48, no.4, pp. 4623-4632.

[13] Sobolev V., Snegirev A., Shinder Y. and Lupulyak S., "Modeling of turbulent Diffusion Combustion in the Jet Flames of the Rectilinear-swirl Burners", The $3^{\text {rd }}$ International Conference, "Heat and Mass transfer and hydrodynamics in swirling flows", Moscow, Russia, 21-23 October, 2008.

[14] Arand G. and Jenny P., "Stochastic nodding of evaporating sprays within a consistent hybrid joint PDF framework", Journal of computational Physics, vol.22, no.8, pp.2063-2081,2009.

[15] Bird R.B., Stewart W.E. and Lighfoot E.N.," Transport Phenomena”, Wiley International Edition, USA, 1980.

[16] Schlichting H., "Boundary Layer Theory ", $6^{\text {th }}$ edition, Mc Graw Hill, New York, USA, 1968.

[17] Instruction manuals of Babcock and Wilcox Company, USA, 2006.

[18] Kubo , I, and Gouldin ,F.C., "Numerical Calculations of Turbulent Swirling Flow ", Fluid Mechanics of Combustion, Journal Fluid Engineering and CSME Conference, Montreal, Quebec May 13-15, 1974.

[19] FLUENT package programme help, 2008.

[20] Reznikov M.I. and Lipov Yu.M.," Steam Boilers of Thermal Power Stations", Mir Publishers Moscow, Russia, 1989.

[21] Ansaldo Co., "Acceptance Test of Steam Generator", Daura Thermal Power Plant Manual, Iraq, 1989.

[22] Hannun R.M., Najim S.E., Rishack Q.A. and Syred N.,"3-D. Aerodynamics And Thermal Prediction For Nassiriya Power Plant Furnace By Using Crude Oil Fuel”, IJAST, UK, Vol.3, No.4, 2011.

Authors Profile

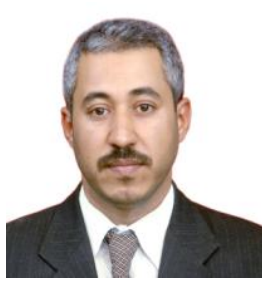

Dr. Rafid M. Hannun received his Ph.D. degree from Basrah University, Iraq in 2009. He is specialist in power and thermal engineering. He went to Cardiff University, Wales, UK to complete his research of Ph.D. study for six months. Master of science in Mechanical Engineering/ Renewable and solar Engineering/ University of Technology/ Baghdad, Iraq2005. He has many research papers published in Iraq and abroad by conferences and journals. He is now the head of Electrical and Electronic Engineering Department and the assistant dean of College of Engineering, Thi-Qar University. He worked as lecturer in college of engineering since 2008. 


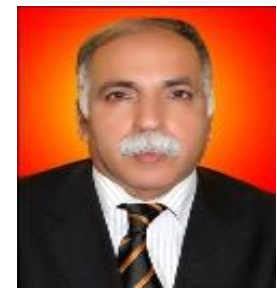

Dr. Salih E. Najim received his Ph.D. degree from Cardiff University, Wales, UK in 1979. $\mathrm{He}$ is specialist in combustion and energy engineering (Proffesor). He is occupying the chancellor of Basrah University position, Iraq. He supervised many students in Ph.D. and M.Sc. thesis in mechanical engineering. He was the dean of College of Engineering, Basrah University. He has many published papers in the World. So, he signed a lot of memorandums of understanding with foreign universities and companies for economical and knowledge cooperation. He worked as lecturer in college of engineering since 1979.

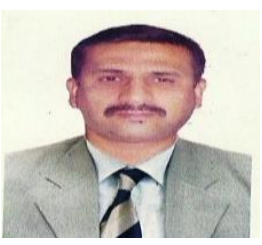

Dr. Qais A. Rishack received his Ph.D. degree from Basrah University, Iraq in 2003. He is Assist.Prof. in Mech. (Thermal) Engineering, Head of Material Eng. Dept., College of Engineering, Basrah University, Iraq. He supervised many students in Ph.D. and M.Sc. thesis in mechanical engineering. He has many published papers in the World. He worked as lecturer in college of engineering since 1994.

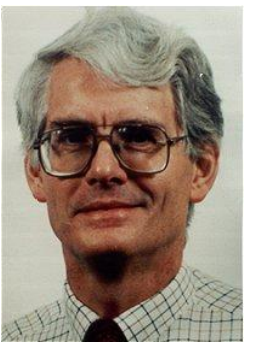

Prof Nick Syred (BEng PhD CEng FInstE FIMechE) graduated with a BEng in Mechanical Engineering in 1965 and obtained a PhD in Power Fluidics in 1969, both at Sheffield University, and was subsequently appointed Research Fellow in the Department of Fuel Technology at Sheffield, under Norman Chigier and John Beer in the area of Swirling Flow and Combustion. He moved to University College, Cardiff in 1974, continuing his work on combustion, swirling vortex and cyclonic flows, centrifugal separation of particles, and heat and mass transfer processes in general. His fields of interest include combustion of gaseous, liquid and solid fuels, heat exchangers, thermofluids, fluidics, water models, flow of steel, hot gas clean-up, cyclone dust separators and gas cleaning in general. During his time at Cardiff, a team of up to 8 research assistants and several research students has been developed, producing 40 $\mathrm{PhD}$ theses and $5 \mathrm{MSc}$ theses. He has obtained research grants amounting to more than $55 \mathrm{M}$ from diverse sources including UKAEA, SERC, British Coal, BP, EEC, Air Products, Coal Processing Consultants Ltd and NSF in areas including biomass and coal combustion, heat exchangers, North Sea flare design, fundamentals of swirling flows with and without liquid/gaseous fuel combustion, power fluidics applied to the nuclear industry, and pressurized fluidized bed combustion, low NOx burners, novel cyclone dust separators, classifiers and gas centrifuges. 